\title{
Real-world experience of switching from Tenofovir Disoproxil Fumarate to Tenofovir Alafenamide in patients with chronic hepatitis B : A Retrospective Study
}

\author{
Pei-Yuan Su ${ }^{\text {Corresp., } 1}{ }^{1}$, Wei-Wen Su ${ }^{1}$, Yu-Chun Hsu ${ }^{1}$, Siou-Ping Huang ${ }^{1}$, Hsu-Heng Yen ${ }^{1,2,3}$ \\ 1 Department of Gastroenterology, Changhua Christian Hospital, Changhua, Taiwan \\ 2 Institute of Medicine, Chung Shan Medical University, Taichung, Taiwan \\ 3 General Education Center, Chienkuo Technology University, Changhua, Taiwan \\ Corresponding Author: Pei-Yuan Su \\ Email address: 111252@cch.org.tw
}

Background: Tenofovir alafenamide (TAF) has good viral suppression efficacy and less adverse effect than tenofovir disoproxil fumarate (TDF). Real-world studies on the antiviral efficacy and safety of switching from TDF to TAF in patients with chronic hepatitis B (CHB) are limited.

Methods: This retrospective study included 167 nucleos(t)ide analogue (NA)-naive patients with CHB. All the patients received TDF at least 12 months before switching and TAF at least 12 months after switching at a single medical center. The Friedman test with Dunn-Bonferroni post hoc tests and repeatedmeasures analysis of variance was used to analyze the effect of complete viral suppression, alanine aminotransferase (ALT) level normalization, renal function changes, body weight, and body mass index in the periods before and after switching.

Results: The mean age and TDF treatment duration were $52 \pm 11$ years and 2.8 years (interquartile range, 1.51-5.15 years), respectively. The complete viral suppression rate was similar between the time of switching and 48 weeks after switching to TAF $(77.8 \%$ vs $76 \%, P=1.000)$. The percentage of alanine aminotransferase (ALT) normalization increased from $26.3 \%$ at TDF start to $81.4 \%(P<0.001)$ at time of switching and $89.2 \%$ at 48 weeks after switching to TAF $(P=0.428)$. The median estimated glomerular filtration rate decreased from $100.09 \mathrm{~mL} / \mathrm{min} / 1.73 \mathrm{~m}^{2}$ at TDF start to $91.97 \mathrm{~mL} / \mathrm{min} / 1.73 \mathrm{~m}^{2}(\mathrm{P}<0.001)$ at the time of switching and stabilized at 48 weeks after switching to $\operatorname{TAF}\left(\left(93.47 \mathrm{~mL} / \mathrm{min} / 1.73 \mathrm{~m}^{2}, \mathrm{P}=\right.\right.$ 1.000). The body weight decreased from $69.2 \pm 12.2 \mathrm{~kg}$ at TDF start to $67.4 \pm 12.1 \mathrm{~kg}(P<0.001)$ at the time of switching to TAF and returned to $68.7 \pm 12.7 \mathrm{~kg}(P<0.001) 48$ weeks thereafter. The body mass index (BMI) decreased from $25 \pm 3.3 \mathrm{~kg} / \mathrm{m}^{2}$ at TDF start to $24.5 \pm 3.3 \mathrm{~kg} / \mathrm{m}^{2}(P=0.002)$ at the time of switching to TAF and returned to $25.1 \pm 3.6 \mathrm{~kg} / \mathrm{m}^{2}(P<0.001) 48$ weeks thereafter.

Conclusions: Our study showed that switching to TAF from TDF had good antiviral effectiveness and stabilized renal function. The body weight and BMI decreased during TDF therapy and regained after switching to TAF. 
1 Real-world Experience of Switching from Tenofovir Disoproxil Fumarate to Tenofovir

2 Alafenamide in Patients with Chronic Hepatitis B: A Retrospective Study

3

4 Short Title: Switching to TAF in patients with HBV

5

6

7 Pei-yuan Su MD ${ }^{1 *}$, Wei-Wen Su MD${ }^{1}$, Yu-Chun Hsu MD ${ }^{1}$, Siou-Ping Huang BS ${ }^{1}$, Hsu-Heng

8 Yen $\mathrm{MD}^{1,2,3}$

9

10

11 Department of Gastroenterology, Changhua Christian Hospital, Changhua, Taiwan

122 Institute of Medicine, Chung Shan Medical University, Taichung, Taiwan

133 General Education Center, Chienkuo Technology University, Changhua, Taiwan

14

15

16

* Correspondence: Pei-yuan Su: 111252@cch.org.tw

17

18 


\section{Abstract}

\section{Background:}

21 Tenofovir alafenamide (TAF) has good viral suppression efficacy and less adverse effect than

22 tenofovir disoproxil fumarate (TDF). Real-world studies on the antiviral efficacy and safety of

23 switching from TDF to TAF in patients with chronic hepatitis B (CHB) are limited.

\section{Methods:}

25 This retrospective study included 167 nucleos(t)ide analogue (NA)-naive patients with CHB.

26 All the patients received TDF at least 12 months before switching and TAF at least 12 months

27 after switching at a single medical center. The Friedman test with Dunn-Bonferroni post hoc

28 tests and repeated-measures analysis of variance was used to analyze the effect of complete viral

29 suppression, alanine aminotransferase (ALT) level normalization, renal function changes, body

30 weight, and body mass index in the periods before and after switching.

\section{Results:}

32 The mean age and TDF treatment duration were $52 \pm 11$ years and 2.8 years (interquartile

33 range, 1.51-5.15 years), respectively. The complete viral suppression rate was similar between

34 the time of switching and 48 weeks after switching to TAF $(77.8 \%$ vs $76 \%, \mathrm{P}=1.000)$. The

35 percentage of alanine aminotransferase (ALT) normalization increased from $26.3 \%$ at TDF start

36 to $81.4 \%(P<0.001)$ at time of switching and $89.2 \%$ at 48 weeks after switching to $\mathrm{TAF}(P=$ 
37 0.428). The median estimated glomerular filtration rate decreased from $100.09 \mathrm{~mL} / \mathrm{min} / 1.73 \mathrm{~m}^{2}$

38 at TDF start to $91.97 \mathrm{~mL} / \mathrm{min} / 1.73 \mathrm{~m}^{2}(\mathrm{P}<0.001)$ at the time of switching and stabilized at 48

39 weeks after switching to TAF $\left(\left(93.47 \mathrm{~mL} / \mathrm{min} / 1.73 \mathrm{~m}^{2}, \mathrm{P}=1.000\right)\right.$. The body weight decreased

40 from $69.2 \pm 12.2 \mathrm{~kg}$ at TDF start to $67.4 \pm 12.1 \mathrm{~kg}(P<0.001)$ at the time of switching to TAF

41 and returned to $68.7 \pm 12.7 \mathrm{~kg}(P<0.001) 48$ weeks thereafter. The body mass index (BMI)

42 decreased from $25 \pm 3.3 \mathrm{~kg} / \mathrm{m}^{2}$ at TDF start to $24.5 \pm 3.3 \mathrm{~kg} / \mathrm{m}^{2}(P=0.002)$ at the time of

43 switching to TAF and returned to $25.1 \pm 3.6 \mathrm{~kg} / \mathrm{m}^{2}(P<0.001) 48$ weeks thereafter.

\section{Conclusions:}

45 Our study showed that switching to TAF from TDF had good antiviral effectiveness and

46 stabilized renal function. The body weight and BMI decreased during TDF therapy and regained

47 after switching to TAF.

48

49

50 Keywords: Tenofovir Disoproxil Fumarate, Tenofovir alafenamide, Chronic hepatitis B, Switch

51

52

53

54 


\section{Introduction}

56 Chronic hepatitis $\mathrm{B}(\mathrm{CHB})$ virus (HBV) infection has an incidence rate of $3.5 \%$ in the global

57 population according to the World Health Organization estimate in 2015 and the highest

58 incidence rates in the Western Pacific (6.2\%) and African regions (6.1\%) $)^{1,2}$. Untreated CHB

59 would lead to cirrhotic complications, liver failure, and/or $\mathrm{HCC}^{3}$. Antiviral therapies with

60 nucleos(t)ide analogues (NA) such as entecavir, tenofovir disoproxil fumarate(TDF), and

61 tenofovir alafenamide (TAF) have been suggested to suppress HBV virus replication and

62 decrease long-term complications and mortality by published guidelines ${ }^{4,5}$.

63 TDF is an antiviral agent with high potency and genetic barrier. However, its long-term

64 adverse effects on renal function and bone mineral density suggest that older patients or patients

65 with deteriorating renal function and/or osteoporosis should use ETV or TAF rather than TDF 4

66 TAF is a prodrug of tenofovir and had a similar antiviral effect on HBV. Two double-blind

67 studies showed that TAF had a high viral suppression rate and less severe bone and renal side

68 effects $^{6,7}$. Recent studies have shown weight increases after switching from TDF to TAF in

69 people living with human immunodeficiency virus (HIV; PLWH) ${ }^{8,9}$. However, only few studies

70 are available about the real-world data on switching from TDF to TAF in patients with CHB.

71 The purpose of this study was to compare the antiviral effect and changes in renal function,

72 weight, and body mass index (BMI) before and after switching from TDF to TAF in a real-world 
73 setting.

74

75

76 Patients and Methods

77 Study population

78 This retrospective study included NA-naive patients with CHB who received TDF at least 12

79 months before switching and TAF at least 12 months after switching at a single medical center.

80 All patients had positive hepatitis B surface antigen (HBsAg) for $>6$ months. Indications for

81 TDF treatment comprised the following: (1) patients with positive HBeAg having ALT levels of

$82 \geq 5$ times the upper limit of normal (ULN); (2) positive HBeAg having HBV deoxyribonucleic

83 acid (DNA) levels of $>20,000 \mathrm{IU} / \mathrm{ml}$ and ALT levels of $>2$ times the ULN; (3) negative $\mathrm{HBeAg}$

84 having with HBV DNA levels of $>2,000 \mathrm{IU} / \mathrm{ml}$ and ALT levels of $>2$ times the ULN for $>3$

85 months; (4) chronic hepatitis B (CHB) having liver decompensation; (5) cirrhosis and HBV

86 DNA levels of $>2,000 \mathrm{IU} / \mathrm{ml}$; or (6) $\mathrm{CHB}$ receiving chemotherapy (prophylaxis of HBV

87 reactivation). The reasons for switching to TAF were all related to the unavailability of TDF due

88 to the hospital pharmacy policy in our hospital. We excluded patients who had received NA or

89 an interrupted antiviral therapy for $>2$ weeks, had concomitant medications with other NAs, or

90 were coinfected with hepatitis C virus (HCV) or HIV. The participants were enrolled between 
91 December 2011 and March 2021.

92

93 Outcomes

94 The primary outcome was the effect of complete viral suppression over the whole period,

95 defined as a HBV DNA level $<10 \mathrm{IU} / \mathrm{mL}$ and normalization of alanine aminotransferase (ALT)

96 level $(<40 \mathrm{IU} / \mathrm{mL})$ at TDF start, at switch from TDF to TAF, and after 48 weeks of TAF. The

97 secondary outcomes were changes in renal function, body weight, and BMI before and after

98 switch from TDF to TAF. We collected clinical data, including HBV viral load, liver and kidney

99 functions, and weight at baseline, the time of switching from TDF to TAF, and 48 weeks after

100 switching to TAF. Baseline was defined as the start of using TDF. The estimated glomerular

101 filtration rate (eGFR) was calculated using the Chronic Kidney Disease Epidemiology

102 Collaboration (CKD-EPI) equation ${ }^{10}$. Cirrhosis was defined based on ultrasonography or

103 radiological evidence of cirrhosis or Fibrosis-4 (FIB-4) scores $\geq 6.5$ or liver histology. The ethics

104 committee of Changhua Christian Hospital approved the study protocol used in the study

105 (institutional review board approval No. 210202). The requirement for informed consent was

106 waived because of the retrospective nature of the study, and the data for analysis were kept

107 anonymous. 


\section{Statistical analysis}

110 Data are expressed as $\mathrm{n} / \mathrm{N}(\%)$, median (interquartile range), or mean \pm standard deviation.

111 The distribution of continuous variables was checked using the one-sample Kolmogorov-

112 Smirnov test. The Friedman test with Dunn-Bonferroni post hoc tests or repeated-measures

113 analysis of variance was used to compare continuous variables in the three time periods, as

114 appropriate. Categorical variables were compared in the three periods by using the Cochran $Q$

115 test. All statistical analyses were performed using SPSS version 22.0 (IBM Corp., Armonk, NY,

116 USA), with two-tailed p values $<0.05$ indicating statistical significance.

\section{Results}

\section{Baseline characteristics at TDF start}

121 Initially, 2606 NA-naive patients with CHB treated with TDF were enrolled. We excluded

1222439 patients because they withdrew from the study early before starting TAF, could not be

123 contacted, received TDF or TAF treatment for $<12$ months, and had data unavailable (HBV viral

124 load or GPT). Finally, 167 patients who switched from TDF to TAF for at least 12 months were

125 included in the study (Figure 1). The patients' mean age was $52 \pm 11$ years, and $120(71.9 \%)$

126 patients were male. The mean BMI and body weight at baseline were $25 \pm 3.3 \mathrm{~kg} / \mathrm{m}^{2}$ and $69.2 \pm$ 
$12712.2 \mathrm{~kg}$, respectively. Of the patients, $109(65.3 \%)$ had cirrhosis while cirrhosis was based on

128 ultrasonography $(n=88)$, computed tomography $(n=10)$, magnetic resonance imaging $(n=3)$, FIB-

1294 scores $\geq 6.5(\mathrm{n}=6)$, or histology $(\mathrm{n}=2)$. The mean TDF treatment duration was 2.8 years

130 (interquartile range (IQR), 1.51-5.15 years). The patients' baseline characteristics are listed in

131 Table 1.

132

133

\section{Virological and biochemical outcomes}

134 The mean HBV viral load at baseline, the time of the switch, and 48 weeks after switching

135 were $7.56 \pm 10.26,1.34 \pm 2.31$, and $1.18 \pm 1.97 \log _{10} \mathrm{IU} / \mathrm{mL}$, respectively. The percentage of

136 complete viral suppression $(\mathrm{HBV}<10 \mathrm{IU} / \mathrm{mL})$ at baseline was $1.2 \%$ and significantly increased

137 to $77.8 \%$ at the time of the switch $(P<0.001)$. The rate was similar between the time of

138 switching and 48 weeks after switching to TAF ( $77.8 \%$ vs $76 \%, P=1.000$; Figure $2 . A)$. The

139 median (IQR) ALT level (IU/mL) at baseline, the time of switching, and 48 weeks after

140 switching were 64 (38-143), 27 (22-39), and 22 (17-31), respectively. The ALT normalization

141 rate $(\leq 40 \mathrm{IU} / \mathrm{mL})$ increased from $26.3 \%$ at baseline to $81.4 \%(P<0.001)$ at the time of

142 switching. The rate slightly increased to $89.2 \%$ at 48 weeks after switching to TAF but not

143 statistically significantly $(P=0.428$; Figure $2 . B)$.

144 The median (IQR) eGFR $\left(\mathrm{mL} / \mathrm{min} / 1.73 \mathrm{~m}^{2}\right)$ decreased from $100.09(87.44-107.03)$ at baseline 
145 to $91.97(77.19-102.31)(P<0.001)$ at the time of switching and stabilized at 48 weeks after

146 switching to TAF (93.34(79.83-101.89), $P=0.414)$. Fifty-three patients had complete data on

147 their Fibrosis-4 (FIB-4) scores at the three time points. The median FIB-4 score decreased from

$1482.93(1.64-4.89)$ at baseline to $1.63(1.17-3.54)$ at 48 weeks after switching to TAF $(P=0.008)$.

149 Other characteristics are listed in Table 2.

150

151 Changes in body weight and BMI

152 The body weight decreased from $69.2 \pm 12.2 \mathrm{~kg}$ at baseline to $67.4 \pm 12.1 \mathrm{~kg}(P<0.001)$ at

153 the time of switching and returned to $68.7 \pm 12.7 \mathrm{~kg}(P<0.001)$ at 48 weeks after switching to

154 TAF. The difference in weight between the baseline and 48 weeks after switching was not

155 statistically different $(P=0.856$; Table 2$)$. The BMI was also decreased from $25 \pm 3.3 \mathrm{~kg} / \mathrm{m}^{2}$ at

156 baseline to $24.5 \pm 3.3 \mathrm{~kg} / \mathrm{m}^{2}(P=0.002)$ at the time of switching and returned to $25.1 \pm 3.6 \mathrm{~kg} / \mathrm{m}^{2}$

$157(P<0.001)$ at 48 weeks after switching to TAF. The difference in BMI between the baseline and

15848 weeks after switching was also not statistically significant $(P=0.642$; Figure 2.C $)$.

159

160

161 Discussion

162 In this retrospective study, we demonstrated the good antiviral effect of short-term treatment 
163 with TAF and better decrease in ALT level after the treatment than at the time of switching and

164 after switching to TDF. The decreased renal function during the TDF therapy was stabilized after

165 switching to TDF. In addition, this real-world study is also one of the first to demonstrate weight

166 changes in patients with chronic hepatitis B infection.

167 Two previous double-blind randomized trials demonstrated the equal effectiveness of viral

168 suppression when compared with TDF to $\mathrm{TAF}^{6,7}$. Another double-blind randomized study about

169 switching from TDF to TAF showed that the viral suppression efficacy of TAF was non-inferior

170 to that of $\mathrm{TDF}^{11}$. Our result also showed a similar result that TDF had good virological response,

171 and the effect was sustained after switching to TAF.

172 TAF increased the ALT normalization rate according to the American Association for the

173 Study of Liver Diseases (AASLD) criteria in the three randomized trials ${ }^{11,12}$. Recently, three

174 retrospective studies in patients with $\mathrm{CHB}$ showed similar findings at 12 to 18 months after

175 switching to TAF, but one study showed that the change was not significant at 6 months after

176 switching to $\mathrm{TAF}^{13-16}$. Our study showed that the decrease in ALT level persisted after switching

177 to TAF, but the ALT normalization rate was similar at the time of switching and 48 weeks after

178 switching. In addition, the FIB-4 index showed persistent improvement during such drug switch.

179 The relationship between TDF/TAF and ALT level may be observed at least 48 weeks after

180 switching, and different normalized criteria would affect these results. The associations of ALT 
181 level between TDF and TAF were also observed in PLWH. The Swiss HIV Cohort Study

182 showed significant decreased of $-11.8 \mathrm{IU} / \mathrm{L}$ per year (95\% CI -17.3 to -6.4$)$ after replacing TDF

183 with TAF in HIV/HBV coinfected patients ${ }^{17}$. The possible mechanisms remain unknown and

184 may be related to the viral suppression or TDF-induced liver injury ${ }^{18}$. Whether the effect is

185 reversible and the relationship between TDF and ALT level in different populations still need

186 confirmation in further large-scale studies.

187 Renal safety is a major concern in long-term TDF therapy, especially in older patients or

188 patients with renal impairment ${ }^{4}$. TDF can induce renal tubular dysfunction, but the detailed

189 mechanism is unclear ${ }^{19}$. TAF is a prodrug of tenofovir (TFV) that has less renal toxicity than

190 TDF. The renal function of patients stabilized at 48 weeks after switching to TAF in a

191 randomized trial and four retrospective studies ${ }^{1113-16}$. The renal outcome was similar in our study

192 in that the median eGFR decreased during TDF therapy $\left(100.09 \mathrm{vs} 91.97 \mathrm{~mL} / \mathrm{min} / 1.73 \mathrm{~m}^{2}\right)$ and

193 stabilized at 48 weeks after switching to TAF $\left(93.47 \mathrm{~mL} / \mathrm{min} / 1.73 \mathrm{~m}^{2}\right)$.

194 Body weight changed after switching from TDF to TAF in two retrospective studies in HIV-

195 positive patients in $2019^{8,20}$. Two large cohort studies showed a mean weight increase of $1.7 \mathrm{~kg}$

196 at 18 months after switching to TAF in Switzerland ${ }^{9}$ and early and pronounced weight gain (1.80

197 to $4.47 \mathrm{~kg} /$ year) in the United States ${ }^{21}$. Recently, a similar finding was found in patients with

198 CHB. The study by Lee et al showed a weight increase from $66.6 \pm 12.1 \mathrm{~kg}$ to $68.1 \pm 12.4$ at 72 
199 weeks after switching to TAF in 61 Asian patients with $\mathrm{CHB}^{22}$. In a randomized non-inferiority

200 trial in Korea, the TAF group showed a significant increase in body weight as compared with the

201 TDF group $(0.71 \mathrm{vs}-0.37 \mathrm{~kg} ; P=0.01)^{23}$. A decrease in weight was observed in our study

202 during the TDF phase $(69.2 \pm 12.2 \mathrm{~kg}$ to $67.4 \pm 12.1 \mathrm{~kg}, P<0.001)$ and returned to the baseline

203 value at 48 weeks after switching to TAF $(67.4 \pm 12.1 \mathrm{~kg}$ to $68.7 \pm 12.7 \mathrm{~kg}, P<0.001)$. A similar

204 result in BMI was also observed in the study. The relationship between weight change and TDF

205 or TAF administration remains unclear and requires investigation in further studies.

206 The study has some limitations. First, this was a retrospective observational study. The

207 laboratory testing could not be performed at regular intervals, and some parameters had missing

208 values. However, the results could still show the statistically significant differences in viral

209 suppression effect and changes in biochemical parameters. Second, we did not measure the

210 serum lipid profiles, fasting glucose and hemoglobin A1c. Some studies showed worsening lipid

211 levels in PLWH after switching to TAF, and the total cholesterol, low-density lipoprotein, and

212 high-density lipoprotein were higher in TAF monotherapy than in TDF monotherapy9,23

213 Additionally, comorbidities, such as diabetes, cardiovascular disease, and malignancy were not

214 adjusted with renal function or weight. These covariates may influence the change in renal

215 function and weight and the association between the covariates and renal function or weight need

216 further investigation. Third, bone mineral density (BMD) was not obtained in our clinical 
217 practice. The effect of TDF on BMD is an important issue especially in patients with osteopenia

218 or osteoporosis $^{12,22}$ that require long-term antiviral therapy.

219 In conclusion, the study demonstrated good efficacy of viral suppression and ALT

220 normalization in patients with CHB who switched from TDF to TAF. The stabilization of renal

221 function was observed at 48 weeks after switching to TAF. In addition, our study revealed

222 weight loss and decreased BMI in the TDF phase and regain of weight and BMI at 48 weeks

223 after switching to TAF. Further investigations are needed to evaluate the long-term effect of the

224 clinical implications of switching to TAF in the future.

225

226

227

228

229 References

230 1. Global Hepatitis Report, 2017. Available at

231 https://www.who.int/publications/i/item/global-hepatitis-report-2017

232 2. Yuen MF, Chen DS, Dusheiko GM, Janssen HLA, Lau DTY, Locarnini SA, Peters MG, Lai CL. Hepatitis B virus infection. Nat Rev Dis Prim. 2018;4(1):1-21.

234 doi:10.1038/nrdp.2018.35 
235 3. Tang LS, Covert E, Wilson E, Kottilil S. Chronic hepatitis B infection a review. J Am Med Assoc. 2018;319(17):1802-1813. doi:10.1001/jama.2018.3795

4. Lampertico P, Agarwal K, Berg T, Buti M, Janssen HLA, Papatheodoridis G, Zoulim F, Tacke F. EASL 2017 Clinical Practice Guidelines on the management of hepatitis B virus infection. J Hepatol. 2017;67(2):370-398. doi:10.1016/j.jhep.2017.03.021 Bzowej NH, Wong JB. Update on prevention, diagnosis, and treatment of chronic hepatitis B: AASLD 2018 hepatitis B guidance. Hepatology. 2018;67(4):1560-1599. doi:10.1002/hep.29800 R, Janssen HLA, Acharya SK, Flaherty JF, Massetto B, Cathcart AL, Kim K, Gaggar A, Subramanian GM, McHutchison JG, Pan CQ, Bruneto M, Izumi N, Marcellin P. Tenofovir alafenamide versus tenofovir disoproxil fumarate for the treatment of patients with $\mathrm{HBeAg}$-negative chronic hepatitis B virus infection: a randomised, double-blind, phase 3, non-inferiority trial. Lancet Gastroenterol Hepatol. 2016;1(3):196-206. doi:10.1016/S2468-1253(16)30107-8

251 7. Chan HL, Fung S, Seto WK, Chuang WL, Chen CY, Kim HJ, Hui AJ, Janssen HAL, Chowdhury A, Tsang TYO, Mehta R, Gane E, Flaherty JF, Massetto B, Gaggar A, 
253 Kitrinos KM, Lin L, Subramanian GM, McHutchison JG, Lim YS, Acharya SK, Agarwal

254 K. Tenofovir alafenamide versus tenofovir disoproxil fumarate for the treatment of

255 HBeAg-positive chronic hepatitis B virus infection: a randomised, double-blind, phase 3,

256 non-inferiority trial. Lancet Gastroenterol Hepatol. 2016;1(3):185-195.

257

doi:10.1016/S2468-1253(16)30024-3

258 8. Schafer JJ, Sassa KN, O’Connor JR, Shimada A, Keith SW, DeSimone JA. Changes in

259 body mass index and atherosclerotic disease risk score after switching from tenofovir

260 disoproxil fumarate to tenofovir alafenamide. Open Forum Infect Dis. 2019;6(10):ofz414.

261 doi:10.1093/ofid/ofz414

262 9. Surial B, Mugglin C, Calmy A, Cavassini M, Günthard HF, Stöckle M,Bernasconi E,

263 Schmid P, Tarr PE, Furrer H, Ledergerber B, Wandeler G, Rauch A. Weight and

264 metabolic changes after switching from tenofovir disoproxil fumarate to tenofovir

265 alafenamide in people living with HIV. Ann Intern Med. 2021;174(6):758-767.

266 doi:10.7326/m20-4853

267 10. Levey AS, Stevens LA, Schmid CH, Zhang YL, Castro AF, Feldman HI, Kusek JW,

268 Eggers P, Van Lente F, Greene T, Coresh J. A new equation to estimate glomerular

269 filtration rate. Ann Intern Med. 2009;150(9):604-612. doi:10.7326/0003-4819-150-9-

270

200905050-00006 
271 11. Lampertico P, Buti M, Fung S, Ahn SH, Chuang WL, Tak WY, Ramji A, Chen CY, Tam

272 E, Bae H, Ma X, Flaherty JF, Gaggar A, Lau A, Liu Y, Wu G, Suri V, Tan SK,

273 Subramanian GM, Trinh H, Yoon SK, Agarwal K, Lim YS, Chan HL. Switching from

274 tenofovir disoproxil fumarate to tenofovir alafenamide in virologically suppressed patients

275 with chronic hepatitis B: a randomised, double-blind, phase 3, multicentre non-inferiority

276 study. Lancet Gastroenterol Hepatol. 2020;5(5):441-453. doi:10.1016/S2468-

$277 \quad 1253(19) 30421-2$

278 12. Agarwal K, Brunetto M, Seto WK, Lim YS, Fung S, Marcellin P, Ahn SH, Izumi N,

279 Chuang WL, Bae H, Sharma M, Janssen HL, Pan, CQ, Çelen MK, Furusyo N, Shalimar

280 D, Yoon KT, Trinh H, Flaherty JF, Gaggar A, Lau AH, Cathcart AL, Lin L, Bhardwaj N,

281 Suri V, Mani SG, Gane EJ, Buti M, Chan HL. 96 weeks treatment of tenofovir

282 alafenamide vs. tenofovir disoproxil fumarate for hepatitis B virus infection. J Hepatol.

283

2018;68(4):672-681. doi:10.1016/j.jhep.2017.11.039

284 13. Toyoda H, Leong J, Landis C, Atsukawa M, Watanabe T, Huang DQ, Liu J, Quek SXZ,

285 Ishikawa T, Arai T, YokohamaK, Chuma M, Takaguchi K, Uojima H, Senoo T, Dang H,

286 Maeda M, Hoang J, Le RH, Yasuda S, Thin KN, Tran S, Chien N, Henry L, Asai A,

287 Fukunishi S, Cheung R, Lim SG, Trinh HN, Nguyen MH. Treatment and renal outcomes

288 up to 96 weeks after tenofovir alafenamide switch from tenofovir disoproxil fumarate in 
289

290

291

292

293

294

295

296

297

298

299

300

301

302

303

304

305

306 routine practice. Hepatology. 2021. Online ahead of print. doi:10.1002/hep.31793

14. Bernstein DE, Trinh HN, Schiff ER, Smith CI, Mospan AR, Zink RC, Fried MW, Lok

AS. Safety and effectiveness of tenofovir alafenamide in usual clinical practice confirms results of clinical trials: TARGET-HBV. Dig Dis Sci. 2021;(0123456789).

doi:10.1007/s10620-021-07033-y

15. Farag MS, Fung S, Tam E, Doucette K, Wong A, Ramji, A, Conway B, Cooper C, Tsoi K, Wong P, Sebastiani G, Brahmania M, Haylock-Jacobs S, Coffin CS, Hansen BE, Janssen HL. Effectiveness and renal safety of tenofovir alafenamide fumarate among chronic hepatitis b patients: real-world study. $J$ Viral Hepat. 2021;28(6):942-950.

doi:10.1111/jvh.13500

16. Alghamdi AS, Alothmani HS, Mogharbel M, Sr HA, Babatin M. Clinical characteristics of hepatitis $b$ virus patients after switching to tenofovir alafenamide fumarate : $a$ retrospective observational study. 2020;12(9). doi:10.7759/cureus.10380

17. Surial B, Béguelin C, Chave JP, Stöckle M, Boillat-Blanco N, Doco-Lecompte T, Bernasconi E, Fehr J, Günthard HF, Schmid P, Walti LN, Furrer H, Rauch A, Wandeler G. Brief Report: Switching From TDF to TAF in HIV/HBV-Coinfected Individuals With Renal Dysfunction-A Prospective Cohort Study. J Acquir Immune Defic Syndr. 2020;85(2):227-232. doi:10.1097/QAI.0000000000002429 
307 18. Kovari H, Sabin CA, Ledergerber B, Ryom L, Reiss P, Law M, Pradier C, Dabis F,

drugs and risk of chronic alanine aminotransferase elevation in human immunodeficiency virus (HIV)-monoinfected persons: the data collection on adverse events of anti-HIV drugs study. Open Forum Infect Dis. 2016;3(1): ofw009. doi:10.1093/ofid/ofw009

312 19. Sano T, Kawaguchi T, Ide T, Amano K, Kuwahara R, Arinaga-Hino T, Torimura T. Tenofovir alafenamide rescues renal tubules in patients with chronic hepatitis B. Life. 2021;11(3):263. doi:10.3390/life11030263

20. Gomez M, Seybold U, Roider J, Härter G, Bogner JR. A retrospective analysis of weight changes in HIV-positive patients switching from a tenofovir disoproxil fumarate (TDF)to a tenofovir alafenamide fumarate (TAF)-containing treatment regimen in one German university hospital in 2015-2017. Infection. 2019;47(1):95-102. doi:10.1007/s15010-0181227-0

320

21. Mallon PW, Brunet L, Hsu RK, Fusco JS, Mounzer KC, Prajapati G, Beyer AP, Wohlfeiler MB, Fusco GP. Weight gain before and after switch from TDF to TAF in a US cohort study. J Int AIDS Soc. 2021;24(4):e25702. doi:10.1002/jia2.25702

323 22. Lee BT, Chang M, Lim C, Bae HS, Fong TL. Bone and renal safety profile at 72 weeks after switching to tenofovir alafenamide in chronic hepatitis B patients. JGH Open. 
325

326

327

328

329

330

331

332

333

334

335

336

337

338

339

340 341 switching to TAF, and 48 weeks after switching to TAF

342

\section{Table legends}

Table 1. Characteristics at TDF start of the study cohort
23. Byun KS, Choi J, Kim J-H, Lee YS, Lee HC, Kim YJ, Yoo BC, Kwon SY, Gwak GY, Lim YS. Tenofovir alafenamide for drug-resistant hepatitis B: a randomized trial for switching from tenofovir disoproxil fumarate. Clin Gastroenterol Hepatol. 2021;S15423565(21)00503-6. Online ahead of print. doi:10.1016/j.cgh.2021.04.045

Table 2. Outcomes of virology, biochemistry, and weight changes at TDF start, the time of 


\section{Figure legends}

344

345 Figure 1. Flow diagram of the patients included in the study.

347 Figure 2. Percentage of complete viral suppression (HBV DNA level $<10 \mathrm{IU} / \mathrm{mL})(\mathrm{A})$,

348 normalization of alanine aminotransferase (ALT) level $(<40 \mathrm{IU} / \mathrm{mL})(\mathrm{B})$, and changes in body

349 mass index (C) at TDF start, the time of switching to TAF, and 48 weeks after switching to TAF.

350 BMI data are shown as mean \pm standard deviation (SD).

351 
Table $\mathbf{1}$ (on next page)

Characteristics at TDF start of the study cohort. 


\begin{tabular}{|c|c|c|}
\hline Characteristics at TDF start & $n=167$ & \multirow{14}{*}{$\begin{array}{l}\text { HBeAg: } \\
\text { hepatitis B } \\
\text { envelope } \\
\text { antigen; } \\
\text { ALT: } \\
\text { alanine } \\
\text { transamina } \\
\text { se; SD: } \\
\text { standard } \\
\text { deviation; } \\
\text { IQR: } \\
\text { interquartil } \\
\text { e range; } \\
\text { HCC: } \\
\text { hepatocellu } \\
\text { lar } \\
\text { carcinoma; } \\
\text { TDF: } \\
\text { tenofovir } \\
\text { (n=1), lung }\end{array}$} \\
\hline Age, years, mean \pm SD & $52 \pm 11$ & \\
\hline Sex, male, n (\%) & $120(71.9 \%)$ & \\
\hline Body mass index, $\mathrm{kg} / \mathrm{m}^{2}$, mean $\pm \mathrm{SD}$ & $25 \pm 3.3$ & \\
\hline Body weight, kg, mean \pm SD & $69.2 \pm 12.2$ & \\
\hline HBV viral load, $\log _{10} \mathrm{IU} / \mathrm{mL}$, mean $\pm \mathrm{SD}$ & $7.56 \pm 10.26$ & \\
\hline HBeAg positive, $\mathrm{n}(\%)$ & $28(19.2 \%)$ & \\
\hline ALT, U/L, median (IQR) & $64(38-143)$ & \\
\hline eGFR, mL/min/1.73 m², median (IQR) & $100.09(87.44-107.03)$ & \\
\hline Cirrhosis, n (\%) & $109(65.3 \%)$ & \\
\hline $\mathrm{HCC}, \mathrm{n}(\%)$ & $20(12.0 \%)$ & \\
\hline Malignancy*, n (\%) & $5(3 \%)$ & \\
\hline Years on TDF, years, median (IQR) & $2.8(1.51-5.15)$ & \\
\hline \multicolumn{2}{|l|}{$\begin{array}{l}\text { disoproxil fumarate } \\
\text { *Malignancy included breast cancer }(n=1) \text {, bl } \\
\text { cancer }(n=1) \text { and leukemia }(n=1)\end{array}$} & \\
\hline
\end{tabular}


Figure 1

Flow diagram of the patients included in the study

2606 NA-naïve patients with chronic hepatitis B infection treated with TDF

2248 patients excluded due to withdrew

before switching to TAF

358 patients who switched from TDF to TAF

191 patients excluded

- 45 Unable to contact

- 110 TDF treatment $<12$ months

- 12 TAF treatment $<12$ months

- 24 Data unavailable (HBV viral load or ALT)

167 patients who switched from TDF to TAF at least 12 months 
Figure 2

Effect of viral suppression, alanine aminotransferase normalization (ALT) and body weight.

Percentage of complete viral suppression (HBV DNA level $<10 \mathrm{IU} / \mathrm{mL}$ ) (A), normalization of ALT level $(<40 \mathrm{IU} / \mathrm{mL})(B)$, and changes in body mass index (C) at TDF start, the time of switching to TAF, and 48 weeks after switching to TAF. BMI data are shown as mean \pm standard deviation (SD).
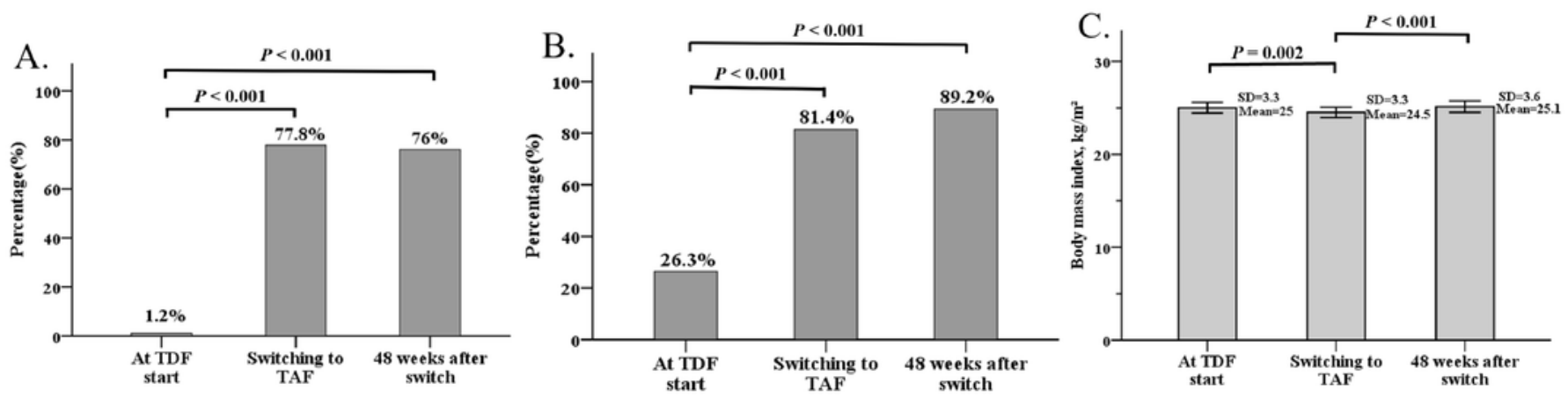


\section{Table 2 (on next page)}

Outcomes of virology, biochemistry, and weight changes at TDF start, the time of switching to TAF, and 48 weeks after switching to TAF. 


\begin{tabular}{|c|c|c|c|c|c|c|c|c|}
\hline \multirow{2}{*}{ Characteristics } & \multirow{2}{*}{$\begin{array}{l}\text { Sample } \\
\text { size }\end{array}$} & \multirow{2}{*}{$\begin{array}{l}\text { At TDF start } \\
\qquad\left(T_{\mathrm{B}}\right)\end{array}$} & \multirow{2}{*}{$\begin{array}{l}\text { Switching to } \\
\text { TAF }\left(T_{0}\right)\end{array}$} & \multirow{2}{*}{$\begin{array}{l}48 \text { weeks after } \\
\text { switching }\left(T_{1}\right)\end{array}$} & \multirow{2}{*}{$P$ value } & \multicolumn{3}{|c|}{ Pairwise comparisons* } \\
\hline & & & & & & $P_{\mathrm{B} 0}$ value & $P_{01}$ value & $P_{\mathrm{B} 1}$ value \\
\hline $\begin{array}{c}\mathrm{HBV} \text { viral load }\left(\log _{10} \mathrm{IU} / \mathrm{mL}\right), \\
\text { mean } \pm \mathrm{SD}\end{array}$ & 167 & $7.56 \pm 10.26$ & $1.34 \pm 2.31$ & $1.18 \pm 1.97$ & $<0.001$ & $<0.001$ & 1.000 & $<0.001$ \\
\hline HBeAg positive, n (\%) & 146 & $28(19.2 \%)$ & $26(17.8 \%)$ & $26(17.8 \%)$ & 0.264 & -- & -- & -- \\
\hline ALT, U/L, median (IQR) & 167 & $64(38-143)$ & $27(22-39)$ & $22(17-31)$ & $<0.001$ & $<0.001$ & $<0.001$ & $<0.001$ \\
\hline $\begin{array}{c}\mathrm{eGFR}, \mathrm{mL} / \mathrm{min} / 1.73 \mathrm{~m}^{2}, \text { median } \\
(\mathrm{IQR})\end{array}$ & 142 & $\begin{array}{c}100.09 \\
(87.44-107.03) \\
\end{array}$ & $\begin{array}{c}91.97 \\
(77.19-102.31) \\
\end{array}$ & $\begin{array}{c}93.34 \\
(79.83-101.89) \\
\end{array}$ & $<0.001$ & $<0.001$ & 1.000 & $<0.001$ \\
\hline Total Bilirubin, mg/dL, median (IQR) & 50 & $0.98(0.57-1.28)$ & $0.8(0.6-1.1)$ & $0.8(0.5-1.1)$ & 0.123 & -- & -- & -- \\
\hline $\begin{array}{l}\text { Platelet count, } \times 10^{3} / \mu \mathrm{L} \text {, median } \\
(\mathrm{IQR})\end{array}$ & 53 & $142(102-194)$ & $160(111-211)$ & $186(135-234)$ & 0.010 & 1.000 & 0.023 & 0.030 \\
\hline FIB-4 score, median (IQR) & 53 & $2.93(1.64-4.89)$ & $1.93(1.42-3.82)$ & $1.63(1.17-3.54)$ & 0.011 & 0.296 & 0.522 & 0.008 \\
\hline Body weight, $\mathrm{kg}$, mean $\pm \mathrm{SD}$ & 136 & $69.2 \pm 12.2$ & $67.4 \pm 12.1$ & $68.7 \pm 12.7$ & $<0.001$ & $<0.001$ & $<0.001$ & 0.856 \\
\hline
\end{tabular}

$1 * P_{\mathrm{B} 0}$ value: $T_{\mathrm{B}}$ vs $T_{0} ; P_{01}$ value: $T_{0}$ vs $T_{1} ; P_{\mathrm{B} 1}$ value: $T_{\mathrm{B}}$ vs $T_{1}$

2 HBeAg: hepatitis B envelope antigen; ALT: alanine transaminase; SD: standard deviation; IQR: interquartile range; TDF: tenofovir

3 disoproxil fumarate; TAF: tenofovir alafenamide; FIB-4: Fibrosis 4

4 